Journal of Telenursing (JOTING)

Volume 1, Nomor 2, Desember 2019

e-ISSN: 2684-8988

p-ISSN: 2684-8996

DOI: https://doi.org/10.31539/joting.v1i2.923

\title{
HUBUNGAN PERAN DAN SIKAP PERAWAT IGD DENGAN PELAKSANAAN TRIAGE BERDASARKAN PRIORITAS
}

\author{
Ni Luh Dita Andrayoni ${ }^{1}$, Made Martini ${ }^{2}$, Nur Widya Putra ${ }^{3}$, Kadek Yudi Aryawan ${ }^{4}$ \\ Sekolah Tinggi Ilmu Kesehatan Buleleng ${ }^{1,2,3,4}$ \\ mademartini20@gmail.com²
}

\begin{abstract}
ABSTRAK
Tujuan penelitian ini untuk mengetahui hubungan peran dan sikap perawat IGD dengan pelaksanaan triage berdasarkan prioritas. Metode penelitian yang digunakan yaitu deskriptif korelasional dengan rancangan cross sectional. Hasil penelitian menunjukkan mayoritas peran perawat baik dengan pelaksanaan triage sebanyak 25 orang $(65,8 \%)$, mayoritas sikap positif dengan pelaksanaan triage sebanyak 23 orang $(60,5 \%)$ dan mayoritas melaksanakan triage sesuai SOP sebanyak 30 orang $(78,9 \%)$. Hasil penelitian dengan uji chi-square p-value $<0,05$. Simpulan, ada hubungan peran dan sikap perawat IGD dengan pelaksanaan triage berdasarkan prioritas.
\end{abstract}

Kata Kunci: Peran, Sikap, Triage

\section{ABSTRACT}

The purpose of this study was to study the relationship between the role and attitudes of emergency room nurses and the implementation of triage based on priorities. The research method used is descriptive correlational with cross sectional design. The results of the study showed the role of nurses with the implementation of triage of 25 people (65.8\%), approved a positive attitude with the implementation of triage of 23 people (60.5\%) and successfully carried out triage according to the SOP of 30 people (78.9\%). The results of the study with the chi-square test p-value $<0.05$. In conclusion, there is a relationship between the role and attitudes of emergency nurses with the implementation of triage based on priorities.

Keywords: Role, Attitude, Triage

\section{PENDAHULUAN}

Kemampuan suatu fasilitas kesehatan secara keseluruhan dalam kualitas dan kesiapan perannya sebagai pusat rujukan penderita dari pra rumah sakit tercermin dari kemampuan instalasi gawat darurat (Hardianti, 2008). Instalasi gawat darurat (IGD) memiliki peran sebagai gerbang utama masuknya penderita gawat darurat. Keadaan gawat darurat merupakan suatu keadaan klinis dimana pasien membutuhkan tindakan medis segera guna menyelamatkan nyawa dan kecacatan lebih lanjut (Undang-Undang Republik Indonesia nomor 44 tentang rumah sakit, 2009).

Instalasi Gawat Darurat (IGD) adalah suatu unit di rumah sakit yang memberikan pelayanan sesuai dengan kebutuhan pasien selama 24 jam. Gawat darurat merupakan keadaan yang mengancam kehidupan karena mengalami gangguan pada nafas dan sirkulasi akibat dari penyakit akut atau trauma, sehingga harus mendapatkan 
pemeriksaan yang tepat dan cepat, jika tidak dilakukan dapat menyebabkan kematian atau kecacatan permanen pada pasien (Depkes RI, 2005).

Rumah sakit khususnya IGD mempunyai tujuan agar tercapainya pelayanan kesehatan yang optimal pada pasien secara cepat dan tepat dalam penanganan tingkat kegawatdaruratan agar mampu mencegah resiko kecacatan dan kematian (to save life andlimb) dengan respon time selama $<5$ menit dan waktu definitif $\leq 2$ jam (Basoeki \& Wirjoatmodjo, 2008). Kematian dan kesakitan pasien dapat diminimalkan atau dicegah dengan berbagai usaha perbaikan dalam bidang pelayanan kesehatan, salah satunya dengan meningkatkan pelayanan kegawatdaruratan (Gurning et al., 2014).

Pelayanan kegawatdaruratan adalah pelayanan yang memerlukan pelayanan cepat dan tepat untuk mencegah kematian dan kecacatan, karena waktu adalah nyawa. Dalam penanganan pasien gawat darurat, IGD memiliki sistem triage dalam melakukan tindakan kegawatdaruratan (Sabrianyanti et al., 2012).

Seorang petugas kesehatan IGD harus mampu bekerja di IGD dalam menanggulangi semua kasus gawat darurat, maka dari itu dengan adanya pelatihan kegawatdaruratan diharapkan setiap petugas kesehatan IGD selalu mengupayakan efisiensi dan efektifitas dalam memberikan pelayanan. Petugas kesehatan IGD sedapat mungkin berupaya menyelamatkan pasien sebanyak-banyaknya dalam waktu sesingkatsingkatnya bila ada kondisi pasien gawat darurat yang datang berobat ke IGD. Pengetahuan, sikap dan keterampilan petugas kesehatan IGD sangat dibutuhkan dalam pengambilan keputusan klinis agar tidak terjadi kesalahan dalam melakukan pemilahan saat triage sehingga dalam penanganan pasien bisa lebih optimal dan terarah (Oman, 2008).

Triage diambil dari bahasa Perancis yaitu Trier yang artinya mengelompokkan atau memilih. Sistem ini pertama kali diperkenalkan dan dikembangkan di medan pertempuran dan digunakan bila terjadi bencana. Di medan pertempuran, triage digunakan untuk menentukan prioritas penanganan pada perang dunia pertama. Klasifikasi ini digunakan oleh para tentara perang untuk mengidentifikasi tentara korban perang yang mengalami luka ringan dengan tujuan agar setelah dilakukan tindakan penanganan dapat kembali kemedan perang (Kartikawati, 2013). Triage adalah suatu proses memilih pasien menurut tingkat kegawatan dan prioritas dalam penanganan pasien (Kartikawati, 2013). Penentuan prioritas penanganan akan dipengaruhi oleh tingkat kegawatan pasien, jumlah pasien yang datang, kemampuan staf IGD, ketersediaan alat pendukung serta ruangan (Kristiani et al., 2015).

Triage harus dilakukan dengan cepat dan tepat, maka diperlukan perawat yang berpengalaman dan berkompeten dalam melakukan triage (Hosnaniah, 2014). Proses triage juga akan berpengaruh pada waktu tanggap atau respons time yang akan diberikan oleh tim medis. Tim medis juga perlu memperhatikan jarak waktu tunggu atau waiting time dalam penanganan pasien (Ardiyani et al., 2015).

Penelitian deskriptif yang dilakukan oleh Sunaryo (2010) tentang beberapa hasil pelaksanaan Triage oleh Perawat di IGD Rumah Sakit Immanuel Bandung antara lain memperlihatkan kegiatan survei primer sesuai dengan standar prosedur dengan kriteria baik sebesar $0 \%$. Prinsip seleksi sesuai prosedur dengan kriteria baik sebesar $0 \%$. Penilaian prioritas sesuai prosedur dengan kriteria baik sebesar 96\%. Kegiatan tindakan triage sesuai prosedur dengan kriteria cukup sebesar $66 \%$. 
Firdaus (2017) dalam penelitiannya membuktikan bahwa penerapan metode Australian Triage Scale atau (ATS) berpengaruh terhadap waiting time yang diberikan. Penerapan ATS memudahkan perawat IGD dalam memberikan intervensi secara tepat dan meminimalkan waiting time pasien.

Berdasarkan studi pendahuluan yang dilakukan pada bulan Februari 2018 didapatkan data dari admisi RSUD Kabupaten Buleleng, kunjungan pasien pada pelayanan IGD dari Januari sampai Desember 2017 sebanyak 14.425 pasien dengan rata-rata kunjungan perbulan sebanyak 1.202 atau sekitar 40 pasien per hari dan total pasien yang meninggal sebanyak 193 pasien (16,1\%). Kunjungan pasien IGD bulan Januari 2018 sebanyak 1.467 pasien dengan rata-rata kunjungan pasien perhari sekitar 49 pasiendengan status true dan false emergency, semakin tingginya kunjungan pasien dengan false emergency menyebabkan pelayanan menjadi lambat dan penanganan tidak sesuai dengan prioritas kegawatdaruratan pasien. Hasil observasi selama studi pendahuluan bahwa kasus kegawatdaruratan tidak dibedakan dalam ruang IGD, bercampurnya ruang triage dengan ruang tindakan dan tidak terdapat jalur warna pada pasien gawat darurat menyebabkan pelaksanaan triage belum berjalan secara optimal. Pada pelaksanaan triage sepenuhnya dilaksanakan oleh perawat tetapi pelaksanaan triage belum sepenuhnya dilakukan di ruang triage karena masih ada beberapa perawat yang tidak melaksanakan triage sesuai SOP rumah sakit.

\section{METODE PENELITIAN}

Penelitian ini merupakan penelitian kuantitatif dengan Desain penelitian deskriptif korelasional rancangan cross sectional. Besar sampel 38 orang menggunakan teknik total sampling. Alat pengumpulan data yang digunakan yaitu lembar kuesioner dan lembar observasi. Analisa data dilakukan dengan menggunakan uji chi-square.

\section{HASIL PENELITIAN}

Tabel. 1

Karakteristik Responden Berdasarkan Usia

\begin{tabular}{ccc}
\hline Usia & Frekuensi (f) & Persentase (\%) \\
\hline $21-34$ & 35 & 92.1 \\
$35-64$ & 3 & 7.9 \\
\hline Total & 38 & 100 \\
\hline
\end{tabular}

Berdasarkan tabel 1 menunjukkan distribusi frekuensi responden berdasarkan usia yaitu sebagian besar berusia 21-34 tahun berjumlah 35 (92.1\%).

Tabel. 2

Karakteristik Responden Berdasarkan Jenis Kelamin

\begin{tabular}{lcc}
\hline Jenis Kelamin & Frekuensi (f) & Persentase (\%) \\
\hline Laki-Laki & 21 & 55.3 \\
Perempuan & 17 & 44.7 \\
\hline Total & 38 & 100 \\
\hline
\end{tabular}


Berdasarkan tabel 2 menunjukkan distribusi frekuensi responden berdasarkan jenis kelamin sebagian besar responden laki-laki berjumlah 21 (55.3\%) orang.

Tabel. 3

Karakteristik Responden Berdasarkan

Tingkat Pendidikan

\begin{tabular}{lcc}
\hline Tingkat Pendidikan & Frekuensi (f) & Persentase (\%) \\
\hline S1 Keperawatan Nurse & 17 & 44.7 \\
S1 Keperawtan & 3 & 7.9 \\
D3 Keperawatan & 18 & 47.4 \\
\hline Total & 38 & 100 \\
\hline
\end{tabular}

Berdasarkan tabel 3 menunjukkan distribusi frekuensi responden berdasarkan tingkat pendidikan yaitu tingkat pendidikan S1 Keperawatan Nurse berjumlah 17 (44.7\%) orang, S1 Keperawatan berjumlah 3 (7.9\%) orang dan dengan tingkat pendidikan D3 keperawatan berjumlah 18 (47.4\%) orang.

Tabel. 4

Karakteristik Responden Berdasarkan

Lama Kerja

\begin{tabular}{lcc}
\hline Lama Kerja & Frekuensi (f) & Persentase (\%) \\
\hline$<5$ Tahun & 32 & 84.2 \\
$\geq 5$ Tahun & 6 & 15.8 \\
\hline Total & 38 & 100 \\
\hline
\end{tabular}

Berdasarkan tabel 4 menunjukkan distribusi frekuensi responden berdasarkan lama kerja yaitu lama kerja $<5$ tahun berjumlah $32(84.2 \%)$ orang dan lama kerja $\geq 5$ tahun berjumlah $6(15.8 \%)$ orang.

Tabel. 5

Karakteristik Responden Berdasarkan Pelatihan yang Pernah Diikuti

\begin{tabular}{lcc}
\hline Jenis Pelatihan & Frekuensi (f) & $\begin{array}{c}\text { Persentase } \\
(\%)\end{array}$ \\
\hline BHD \& BTCLS & 12 & 31.6 \\
BHD, BTCLS, \& ATS & 13 & 34.2 \\
BTCLS \& ATS & 2 & 5.3 \\
BHD \& BTCLS & 6 & 15.8 \\
BHD, BTCLS, Resusitasi Neonatus, \& ATS & 3 & 7.9 \\
BHD, BTCLS, ATLS, Resusitasi Neonatus \& ATS & 2 & 5.3 \\
\hline TOTAL & 38 & 100 \\
\hline
\end{tabular}

Berdasarkan tabel 5 menunjukkan distribusi frekuensi responden berdasarkan jenis pelatihan yang diikuti yaitu pelatihan BHD dan BTCLS berjumlah 12 (31.6\%) orang, pelatihan BHD, BTCLS, dan ATS berjumlah 13 (34.2\%) orang, pelatihan BTCLS dan ATS berjumlah $2(5.3 \%)$ orang, pelatihan BHD dan BTCLS berjumlah $6(15.8 \%)$ orang, pelatihan BHD, BTCLS, resusitasi neonatus, dan ATS berjumlah 3 (7.9\%) orang dan pelatihan BHD, BTCLS, ATLS, resusitasi neonatus dan ATS berjumlah $2(5.3 \%)$ orang. 
Tabel. 6

Peran Perawat Instalasi Gawat Darurat (IGD) dengan

Pelaksanaan Triage Berdasarkan Prioritas

\begin{tabular}{lcc}
\hline Peran Perawat & Frekuensi (f) & Persentase (\%) \\
\hline Cukup & 11 & 28.9 \\
Baik & 27 & 71.1 \\
\hline Total & 38 & 100 \\
\hline
\end{tabular}

Berdasarkan tabel 6 menunjukkan distribusi frekuensi responden berdasarkan peran perawat yaitu peran cukup berjumlah $11(28.9 \%)$ orang dan peran baik berjumlah 27 (71.1\%) orang.

Tabel. 7

Sikap Perawat Instalasi Gawat Darurat (IGD) dengan

Pelaksanaan Triage Berdasarkan Prioritas

\begin{tabular}{lcc}
\hline Sikap Perawat & Frekuensi (f) & Persentase (\%) \\
\hline Negatif & 14 & 36.8 \\
Positif & 24 & 63.2 \\
\hline Total & 38 & 100 \\
\hline
\end{tabular}

Berdasarkan tabel 7 menunjukkan distribusi frekuensi responden berdasarkan sikap perawat yaitu sikap negatif berjumlah $14(36.8 \%)$ orang dan dengan sikap positif berjumlah $24(63.2 \%)$ orang.

Tabel. 8

Pelaksanaan Triage Perawat Instalasi Gawat Darurat (IGD) dengan

Pelaksanaan Triage Berdasarkan Prioritas

\begin{tabular}{lcc}
\hline Pelaksanaan TRIAGE & Frekuensi (f) & Persentase (\%) \\
\hline Tidak Sesuai & 8 & 21.1 \\
Sesuai & 30 & 78.9 \\
\hline Total & 38 & 100 \\
\hline
\end{tabular}

Berdasarkan tabel 8 menunjukan distribusi frekuensi responden berdasarkan pelaksanaan triage yaitu pelaksanaan tidak sesuai berjumlah $8(21.1 \%)$ orang dan dengan pelaksanaan triage sesuai berjumlah 30 (78.9\%) orang.

Tabel. 10

Analisis Hubungan antara Peran Perawat dengan Pelaksanaan Triage

\begin{tabular}{|c|c|c|c|c|c|c|c|}
\hline \multirow{2}{*}{$\begin{array}{l}\text { Peran } \\
\text { Perawat }\end{array}$} & \multicolumn{4}{|c|}{ Pelaksanaan TRIAGE } & \multirow[t]{2}{*}{$\mathrm{N} \%$} & \multirow{2}{*}{$\begin{array}{l}\text { Contingency } \\
\text { Coefficient }\end{array}$} & \multirow[t]{2}{*}{$P$ Value } \\
\hline & $\begin{array}{l}\text { Tidak } \\
\text { Sesuai }\end{array}$ & $\%$ & Sesuai & $\%$ & & & \\
\hline Cukup & 6 & 13.2 & 5 & 15.8 & 28.9 & 0.707 & 0.002 \\
\hline Baik & 2 & 5.3 & 25 & 65.8 & 71.1 & & \\
\hline Total & 8 & 21.1 & 30 & 78.9 & 100.0 & & \\
\hline
\end{tabular}


Berdasarkan tabel 10 menunjukkan bahwa peran perawat baik sebanyak 25 (65.8\%) orang dengan pelaksanaan triage sesuai. Hasil uji korelasi chi-squere diperoleh $p$-value yaitu sebesar 0,002 maka $p$-value $<\alpha(0,05)$ maka ada hubungan antara Peran Perawat dengan pelaksanaan triage di IGD RSUD Kabupaten Buleleng. Nilai contingency coefficient didapatkan 0.707 yang menunjukan tingkat keeratan hubungan peran perawat dengan pelaksanaan triage.

Tabel. 11

Analisis Hubungan antara Sikap Perawat dengan Pelaksanaan Triage

\begin{tabular}{lccccccc}
\hline \multirow{2}{*}{$\begin{array}{l}\text { Sikap } \\
\text { Perawat }\end{array}$} & \multicolumn{3}{c}{ Pelaksanaan TRIAGE } & N \% & $\begin{array}{l}\text { Contingency } \\
\text { Coefficient }\end{array}$ & P Value \\
\cline { 2 - 6 } & $\begin{array}{c}\text { Tidak } \\
\text { Sesuai }\end{array}$ & $\begin{array}{c}\text { Sesu } \\
\text { ai }\end{array}$ & $\%$ & & & \\
\cline { 1 - 7 } Negatif & 7 & 18.4 & 7 & 18.4 & 36.8 & 0.654 & 0.004 \\
\cline { 1 - 7 } Positif & 1 & 2.6 & 23 & 60.5 & 63.2 & & \\
\hline Total & 8 & 21.1 & 30 & 78.9 & 100.0 & & \\
\hline
\end{tabular}

Berdasarkan tabel 11 menunjukkan bahwa sikap perawat positif sebanyak 23 $(60.5 \%)$ orang dengan pelaksanaan triage sesuai. Hasil uji korelasi Chi-Squere diperoleh $p$-value yaitu sebesar 0,004 maka $p$-value $<\alpha(0,05)$ maka ada hubungan antara sikap perawat dengan pelaksanaan triage di IGD RSUD Kabupaten Buleleng. Nilai contingency coefficient didapatkan 0.654 yang menunjukan tingkat keeratan hubungan sikap perawat dan pelaksanaan triage.

Tabel. 12

Analisis Regresi Linier Berganda antara Sikap dan Peran Perawat dengan Pelaksanaan Triage

\begin{tabular}{cccc}
\hline Variabel & VIF & R Square & OR \\
\hline Sikap & 2.04 & 0.332 & 1.719 \\
Peran & 2.04 & & 2.702 \\
\hline
\end{tabular}

Berdasarkan tabel 12 menunjukkan seberapa jauh atau seberapa besar variabel independen mempengaruhi variabel dependen. Hasil anlisis regresi liner berganda diperoleh nilai R squere sebesar 0.332. Nilai $O R$ pada variabel sikap didapatkan sebesar 1.719 dan pada variabel peran didapatkan sebesar 2.702 .

\section{PEMBAHASAN}

Usia dikategorikan berdasarkan teori yang dikemukakan oleh Wong, dkk (2008) yang dibagi kedalam usia dewasa awal (21-34 tahun), dewasa tengah (35-64 tahun) dan dewasa akhir ( $\geq 65$ tahun). Pada penelitian ini didapat mayoritas responden berada pada rentangusia 21-34 tahun sebanyak 35 orang $(92,1 \%)$ dan usia 35-64 tahun sebanyak 3 orang (7,9\%). Menurut Budiman \& Riyanto (2014) dan Notoatmodjo (2014) usia mempengaruhi daya tangkap dan pola pikir seseorang, semakin bertambah usia maka semakin berkembang daya tangkap dan pola pikirnya.

Dari penelitian ini didapatkan mayoritas responden berjenis kelamin laki-laki sebanyak 21 orang $(55,3 \%)$ dan perempuan sebanyak 17 orang $(44,7 \%)$. Hal ini menunjukan bahwa perawat IGD laki-laki lebih banyak dibutuhkan tenaganya untuk menangani kasus yang cukup serius dibandingkan perawat perempuan. 
Latar belakang pendidikan perawat IGD Rumah Sakit Umum Kabupaten Buleleng adalah D3 keperawatan, S1 keperawatan dan SI keperawatan Ners. Hasil penelitian menunjukkan bahwa mayoritas responden memiliki pendidikan terakhir D3 keperawatan sebanyak 18 orang $(47,4 \%)$, S1 keperawatan sebanyak 3 orang $(7,9 \%)$ dan S1 keperawatan Ners sebanyak 17 orang (44,7\%). Sejalan dengan penelitian yang dilakukan oleh Setriani et al., (2018) yang menunjukkan bahwa sebagian besar responden memiliki latar belakang pendidikan D3 Keperawatan. Potter \& Perry (2012) menyebutkan bahwa lulusan diploma dan sarjana muda merupakan sumber daya yang paling signifikan dalam dunia kerja.

Hasil penelitian menunjukkan bahwa responden terbanyak adalah yang bekerja < 5 tahun sebanyak 32 orang $(84,2 \%)$ dan $\geq 5$ tahun sebanyak 6 orang $(15,8 \%)$. Lama bekerja seseorang maka akan menentukan banyak pengalaman yang didapatkannya. Budianto \& Riyanto (2014) mengatakan bahwa tingkat kematangan seseorang dalam berfikir dan berperilaku dipengaruhi oleh pengalaman sehari-hari. Lama bekerja seorang perawat IGD untuk dapat melaksanakan triage minimal memiliki masa kerja $\geq 6$ bulan.

Mubarak (2012) menjelaskan bahwa lama bekerja dapat menjadikan seseorang memperoleh pengetahuan baik secara langsung maupun tidak langsung, pengetahuan dapat diperoleh dari pengalaman selama bekerja. Peneliti berpendapat pengalaman kerja dapat mempengaruhi pengetahuan seseorang. Pengalaman bekerja merupakan salah satu

sumber pengetahuan atau suatu cara untuk membuktikan pengetahuan yang telah dimiliki oleh seseorang. Pengalaman juga merupakan hal yang dialami sendiri oleh seseorang secara langsung. Seseorang melalui pengalamannya memperoleh banyak halhal baru. Hal-hal baru yang didapati saat bekerja dapat menambah pengetahuannya dalam mengerjakan pekerjaan tersebut.

Berdasarkan hasil penelitian mayoritas perawat IGD telah mengikuti pelatihan BHD, BTCLS dan ATS sebanyak 13 orang (34,2\%), pelatihan BHD dan BTCLS sebanyak 12 orang $(31,6 \%)$, pelatihan BTCLS dan ATS sebanyak 2 orang $(5,3 \%)$, pelatihan BHD dan BTCLS sebanyak 6 orang (15,8\%), pelatihan BHD, BTCLS, resusitasi neonatus dan ATS sebanyak 3 orang (7,9\%) dan pelatihan BHD, BTCLS, ATLS, resusitasi neonatus dan ATS sebanyak 2 orang (5,3\%). Pelatihan yang didapat akan menambah pengetahuan dan skill seseorang dalam membantu pasien gawat darurat. Perawat IGD yang dapat melakukan tindakan triage minimal pernah mengikuti pelatihan kegawatdaruratan.

Triage diambil dari bahasa Perancis yaitu Trier yang artinya mengelompokkan atau memilih. Sistem ini pertama kali diperkenalkan dan dikembangkan di medan pertempuran dan digunakan bila terjadi bencana. Di medan pertempuran, triage digunakan untuk menentukan prioritas penanganan pada perang dunia pertama. Klasifikasi ini digunakan oleh para tentara perang untuk mengidentifikasi tentara korban perang yang mengalami luka ringan dengan tujuan agar setelah dilakukan tindakan penanganan dapat kembali kemedan perang (Kartikawati, 2013).

Dari penelitian yang telah dilakukan didapatkan hasil bahwa dari 27 orang responden melakukan peran baik yang melaksanakan triage berdasarkan prioritas sesuai dengan prosedur sebanyak 25 orang responden $(65,8 \%)$. Hasil statistik uji korelasichisquare diperoleh $p$-value $<\alpha(0,002<0,05)$ maka terdapat hubungan antara peran perawat dengan pelaksanaan triage di IGD RSUD Kabupaten Buleleng. Peran perawat diukur melalui kemampuan dan keterampilan kerjanya. Dimana dapat diperoleh melalui pendidikan, pelatihan dan masa kerja, semakin lama waktu yang digunakan oleh seseorang untuk pendidikan dan pelatihan maka akan semakin tinggi pula kinerjanya. 
Berdasarkan penelitian yang sudah dilakukan didapatkan hasil bahwa dari 24 orang responden yang memiliki sikap positif yang melaksanakan triage berdasarkan prioritas yang sesuai prosedur sebanyak 23 orang responden (60,5\%). Hasil statistik uji chi-square didapatkan $p$ value $<\alpha(0,004<0,05)$ sehingga terdapat hubungan antara sikap perawat IGD dengan pelaksanaan triage berdasarkan prioritas. Menurut Notoatmodjo (2014) mengatakan bahwa tindakan yang dilakukan individu cenderung dipengaruhi oleh informasi dan pengetahuan yang dimilikinya. Sikap yang positif terhadap suatu informasi yang diterima seseorang dapat mempengaruhi setiap tindakan yang akan dilakukannya. Seseorang yang bersikap positif akan cenderung untuk memahami dengan benar setiap informasi atau pengetahuan yang ada, sebaliknya sikap yang negatif terkadang akan memberikan pemahaman informasi yang salah.

Hasil uji multivariat menunjukan seberapa jauh atau seberapa besar variabel independen mempengaruhi variabel dependen. Hasil anlisis regresi linier berganda diperoleh nilai $\mathrm{R}$ squere sebesar 0.332. Nilai $O R$ pada variabel sikap didapatkan sebesar 1.719 dan pada variabel peran didapatkan sebesar 2.702, jadi dapat disimpulkan bahwa variabel independen yaitu peran perawat memiliki hubungan yang paling kuat terhadap pelaksanaan triage dilihat dari nilai OR peran sebesar 2.702. Peran perawat merupakan suatu cara untuk menyatakan suatu aktivitas perawat dalam praktik yang telah menyelesaikan pendidikan formalnya, diakui dan diberikan tanggungjawab keperawatan secara professional sesuai dengan kode etik profesinya. Menurut Rifiani \& Sulihandari (2013) terdapat delapan jenis peran perawat antara lain: peran care giver, client advocate, counsellor, educator, collaborator, coordinator, change agent dan counsultan.

Penelitian terkait triage telah dilakukan oleh beberapa peneliti sebelumnya. Penelitian yang dilakukan oleh Hosnaniah (2014) tentang Pelaksanaan triage di unit gawat darurat RS Raksa Waluyo Kota Mojokerto menyatakan bahwa perawat IGD yang melakukan triage masih sangat minim, dari 7 orang responden hanya 4 responden yang melakukan triage sesuai dengan Standar Operational Prosedur (SOP) Rumah sakit. Penelitian yang dilakukan Ardiyani et al., (2015) tentang analisis peran perawat tentang triage terhadap waiting time dan length of stay di IGD RS dr. Saiful Anwar Malang menyatakan bahwa, perawat sangat berpengaruh dalam pelaksanaan triage terhadap waiting time. Kesesuaian waiting time berdasarkan standar terlihat terutama pada perawat yang menjalankan peran dengan baik. Firdaus (2017) dalam penelitiannya membuktikan bahwa penerapan metode Australian Triage Scale atau (ATS) berpengaruh terhadap waiting time yang diberikan. Penerapan ATS memudahkan perawat IGD dalam memberikan intervensi secara tepat dan meminimalkan waiting time pasien.

\section{SIMPULAN}

Setelah dilakukan penelitian tentang hubungan peran dan sikap perawat IGD dengan pelaksanaan triage berdasarkan prioritas didapatkan bahwa perawat mayoritas memiliki peran baik terhadap pelaksanaan triage. Mayoritas perawat memiliki sikap positif dengan pelaksanaaan triage dan sebagian besar perawat melaksanakan triage sesuai dengan SOP sebanyak.

Hasil penelitian menunjukkan bahwa ada hubungan peran dan sikap perawat IGD dengan pelaksanaan triage berdasarkan prioritas. Hasil analisis regresi linier berganda menunjukkan bahwa variabel peran menunjukkan hubungan yang paling kuat terhadap pelaksanaan triage dilihat dari nilai OR sebesar 2.702 . 


\section{SARAN}

Diharapkan hasil penelitian ini dapat dijadikan sumber informasi dan wawasan tambahan untuk menjalankan tindakan keperawatan. Hasil penelitian ini masih banyak kekurangan karena peneliti belum dilakukan secara maksimal dan belum membahas tentang respon time dan length of stay di ruang IGD.

\section{DAFTAR PUSTAKA}

Ardiyani, V. M., Andri, M. T., \& Eko, R. (2015). Analisis Peran Perawat Triage terhadap Waiting Time dan Length of Stay pada Ruangan Triage di Instansi Gawat Darurat Rumah Sakit dr Saiful Anwar Malang. Jurnal Care, 3(1), 39-50. Diperoleh dari: https://jurnal.unitri.ac.id

Basoeki, B., \& Wirjoatmodjo, W. (2008). Penanggulangan Penderita Gawat Darurat Anestesiologi dan Reanimasi. Surabaya: FK. Unair

Budiman, B., \& Riyanto, R. (2014). Kapita Selekta Kuesioner: Pengetahuan dan Sikap dalam Penelitian Kesehatan. Jakarta: Salemba Medika

Departemen Kesehatan RI. (2005). Pedoman Pelayanan Keperawatan Gawat Darurat di RS. Jakarta

Firdaus, M. N. (2017). Penerapan ATS terhadap Waiting Time Klien. Prosiding Seminar Nasional, 34-37. Diperoleh dari: http://ejurnalp2m.stikesmajapahitmojokerto.ac.id

Gurning, Y., Karim, D., \& Misrawati, M. (2014). Hubungan Tingkat Pengetahuan dan Sikap Petugas Kesehatan IGD terhadap Tindakan Triage Berdasarkan Prioritas. Jurnal online mahasiswa, 1-9. Diperoleh dari: http://jom.unri.ac.id

Hardianti, H. (2008). Gambaran Kerja Perawat Pelaksana Unit Instalasi Gawat Darurat. Jakarta: Trans Info Media

Hosnaniah, J. (2014). Pelaksanaan Triage di Unit Gawat Darurat. Diperoleh dari: http://repository.poltekkesmajapahit.ac.id

Kartikawati, N. D. (2013). Buku Ajar Dasar- Dasar Keperawatan Gawat Darurat. Jakarta: Salemba Medika

Kristiani, Y., Ani, S., \& Ardhiyani, V. (2015). Hubungan Waiting Time dengan Kepuasan Pasien Prioritas 3 di Instalasi Gawat Darurat RS Waluya Sawahan Malang. Jurnal Care, 3(1), 33-38. Diperoleh dari: https://jurnal.unitri.ac.id

Mubarak, W. I. (2012). Promosi Kesehatan Kebidanan. Jakarta: Salemba Media

Notoatmodjo, S. (2014). Promosi Kesehatan dan Prilaku Kesehatan. Jakarta: Rineka Cipta

Oman, O. (2008). Panduan Belajar Keperawatan Emergensi. Jakarta: EGC

Potter, P. A., \& Perry, S G. (2012). Buku Ajar Fundamental Keperawatan. Jakarta: EGC

Rifiani, R., \& Sulihandari, S. (2013). Prinsip-Prinsip Dasar Keperawatan. Jakarta: Dunia Cerdas

Sabrianyanti, W. O. N. I., Islam, A. A., \& Gaus, S. (2012). Waktu Tanggap Penanganan Kasus pada Response Time di Ruangan Bedah dan Non-Bedah IGD RS dr. Wahidin Sudirohusodo. Universitas Hasanuddi. http//pasca.unhas.ac.id

Setriani, V., Dewi, W. N., \& Karim, D. (2018). Identifikasi Pengetahuan Perawat Gawat Darurat tentang Triage. JOM FKp, 5(2), 730-736

Sunaryo, Y. E. (2010). Pelaksanaan Triage oleh Perawat di Instalasi Gawat Darurat Rumah Sakit Immanuel Bandung. Diperoleh tanggal 11 Agustus 2013 dari: www.rsimmanuel.com/index.php?option=com_content $\&$ view 
2019. Journal of Telenursing (JOTING) 1 (2) 294-303

Undang-Undang No. 44 (2009). Peraturan Rumah Sakit. Diperoleh dari: www.kemendagri.go.id/media/document/2009/...UU-No.44-2009.doc 